\title{
PERFORMANCE MANAGEMENT OF NATIONAL SPORT ORGANISATIONS: A HOLISTIC THEORETICAL MODEL
}

\author{
Lobone Lloyd Kasale, Mathieu Winand \& Leigh Robinson, University of Stirling
}

To cite this article: Lobone Lloyd Kasale, Mathieu Winand \& Leigh Robinson (2018): Performance Management of National Sport Organisations: A holistic theoretical model, Sport Business Management: An International Journal, DOI: 10.1102/SBM-10-2017-0056

\begin{abstract}
Purpose - Organisational performance of sport organisations has been studied over the last three decades. However, little attention was paid towards performance management compared to performance measurement. This paper closes this research gap by establishing a holistic perspective for performance management (PM) of National Sport Organisations (NSOs) that accounts for their uniqueness, the interdependence of their operating systems and their relationship with their environments. Furthermore, this paper presents a holistic model of PM for NSOs.

Method - The model was developed from a literature review process and uses the macro, meso and micro analytic framework to describe external and internal environmental influences that affect the PM of NSOs.

Findings -The NSO's ability to respond to the dynamics of their external environment by implementing organisational processes that account for the resources available and their structural designs influences their PM. Furthermore, the ability of the individuals within NSO to create enabling environments for PM, influences organisational efficiency and effectiveness.

Research implications: This paper contributes to sport management literature on PM of NSOs, and informs sport managers on ways to improve organisational performance by implementing holistic approaches to PM.

Originality and value - This is the first study that takes a holistic approach to PM of NSO and depicts the specific elements that play a crucial role in managing NSO's multidimensional performance.
\end{abstract}

Keywords - National Sport Organisations, Performance management, Holistic theoretical model

Paper type - Literature review 


\section{INTRODUCTION}

Performance management (PM) has become increasingly important to National Sports Organisations (NSOs) as they aim to operate like business entities that control the achievement of their objectives and the satisfaction of their stakeholders (Perck et al., 2016). NSOs also called National Sport Federations/Associations/ Governing Bodies are non-profit organisations that serve to organise mass participation and elite sport programs for their members in their respective countries (Shilbury and Moore, 2006). They compete for resources with other non-profit organisations in their environments and in most cases, they financially rely on stakeholders such as government and corporate sponsors, (Winand et al., 2010). As such, they are required by their stakeholders to facilitate operating environments that enable them to be competitive and to account to their funders through performance-based approaches (O'Boyle and Hassan, 2014; Winand et al., 2013). This creates a need for NSOs to develop and implement PM models that help them to monitor the attainment of their goals and ensure the satisfaction of their stakeholders (O'Boyle and Hassan, 2014).

The concept of PM is difficult to define because it is underpinned by disciplines that include economics, finance and human resources, and as such, is interdependent on other management control systems such as strategy, structure, and culture (Byers et al., 2012; MacLean, 2016). Winand et al. (2014) and Nowy et al. (2015) further noted that the different perspectives of defining success, also made defining PM challenging. However, according to MacLean (2016) PM should be defined from a holistic perspective that accounts for the context of the organisation and the interdependence of its operating systems. Furthermore, Ferreira and Otley (2009) highlight that PM should also account for the influence of both external (environmental conditions) and internal (structure, processes, capabilities, people) environmental factors as they impact on organisational processes. Biticti, Carrie and 
McDevitt (1997) described PM as a process that provides a proactive closed loop control system where strategies are deployed to all business processes, and feedback is obtained through a performance measurement system to enable appropriate management decisions. While this definition does not account for the influence of the external environment, it accounts for the interdependence of the processes and activities that an organisation engages in. This description also considers the individuals that drive organisational processes and the use of feedback from performance measurement to inform appropriate management decisions. Therefore, Biticti et al.'s (1997) definition provides a more holistic picture of PM.

PM models such as the Total Quality Management (TQM), ISO 9001, Six-Sigma, Balanced Scorecard and Performance Prism have been developed over time to monitor the efficiency and effectiveness of organisational processes. As the models developed over time, there was a shift from emphasis on financial measures to the inclusion of non-financial measures of performance (Robinson, 2010) and a consideration for the influence of the environment (Ferreira and Otley, 2009). While these developments were suitable to NSOs because they have less emphasis on financial gains compared to sport and social outcomes (O'Boyle and Hassan, 2014; Winand et al., 2010), their use among NSOs may present operational challenges due to the uniqueness of these organisations. NSOs are unique because firstly, they are regulated through a sport system by international and continental sport organisations that they affiliate to (Bayle, 2005; Winand et al., 2010). Secondly, they pursue various goals that reflect the multiple expectations of their stakeholders (Papadimitriou and Taylor, 2000; Shilbury and Moore, 2006). Thirdly, NSOs are governed by volunteers who take charge over paid operational staff (Papadimitriou, 2007; Winand et al., 2010). And lastly, NSOs report to clubs, teams and individuals who form their general membership (Bayle, 2005). Therefore, these unique characteristics of NSOs have implications on their operating environment and 
their PM. As such, there is a need for development and implementation of NSO specific PM models that address their uniqueness.

This paper aims to conceptualise on the PM of NSOs from a holistic point of view, that accounts for the NSO's whole environment made up of external and internal environmental influences, the interdependence of their operating systems and the uniqueness of their context. The paper serves to provide understanding on the practice PM as it exists among NSOs and to identify key elements that play a role in the process. This paper further demonstrates the interaction between the various operating environments of the NSO and proposes a holistic model of PM for NSOs. Additionally, the paper highlights and discusses avenues for further research on the PM of NSOs and contributes to sport management literature on PM of NSOs that is currently lacking (O'Boyle and Hassan, 2014). The paper further serves to inform sport managers on ways to improve organisational performance by implementing holistic PM approaches. In the next section a theoretical framework that underpins this study is presented, followed by a description of the methods used in this study. A section on the NSOs' operating environments is presented next, and a discussion on the components of PM models follows. The paper expands to present and discuss the proposed holistic model of PM for NSOs, avenues for future research as presented by the model and the study's practical utility. The paper closes with concluding remarks that detail the study's contribution to knowledge.

\section{THEORETICAL FRAMEWORK}

This study is underpinned by organisational theories that include contingency, stakeholder, resources dependence, institutional and institutional work theories. These theories serve to 
provide a theoretical foundation with which to conceptualise PM from a holistic point of view and to identify influences that affect the PM of NSOs. Furthermore, these theories are used in this study to describe the external and internal operating environments of NSOs and to develop a holistic model of PM that accounts for the uniqueness of NSOs, the interdependence of their operating systems and the influence of their external and internal environments. The stakeholder and resource dependence theories are discussed next.

\section{Stakeholder and resource dependence theories}

The stakeholder theory posits that organisations exist to create value for stakeholders, and they should manage their relationship with their stakeholders to ensure their survival and better performance (Freeman, 1984). NSOs have many stakeholders who perform different

roles for the attainment of their mission, and some of the stakeholders serve to provide them with resources (Vos et al., 2011; Wicker et al., 2012). For more understanding of the relationship between the NSO and the stakeholders who provide them with resources, the resource dependency theory has also been used in this study. The basic assumption of the resource dependence theory is that organisations that are unable to internally generate the resources they need, interact with other organisations within their environments to receive these resources (Pfeffer and Salancik, 1978). While the resources received reduces their financial vulnerability, their autonomy and ability to act independently is greatly reduced (Pfeffer and Salancik, 1978). The resource dependence theory further notes that the organisations that control the critical resources has the power to influence the behaviour of the organisation that depends on the resources (Pfeffer and Salancik, 1978). Therefore, the stakeholders that provide resources to NSOs may influence their organisational processes with implications on how they manage their performance. As such, the stakeholder and resource dependence theories provide a lens with which to describe the relationship between 
the NSOs and their funding stakeholders, as an external environmental factor that influences PM. Consequently, there is a further need to consider other external environmental factors, and how they influence changes to the NSOs' internal environment and the institutional theory specifically institutional isomorphism has been used in this study to describe this and is discussed in the next section.

\section{Institutional theory - institutional isomorphism}

The central idea of institutional isomorphism is that organisations respond to external environmental influences by adopting processes and practices that ensure their survival (DiMaggio and Powell, 1983). It encompasses three elements, and these include coercive, mimetic and normative pressures (DiMaggio and Powell, 1983). Coercive pressures push organisational procedures and structures to conform to best practice, as influenced by the dependence of an organisation on another or on political influence (DiMaggio and Powell, 1983). Mimetic pressures on the other hand relate to organisations imitating or mimicking successful peer organisations (DiMaggio and Powell, 1983). While normative pressures are a response to professionalization (DiMaggio and Powell, 1983). Institutional isomorphism is used in this study to explain the influence of external environmental pressures and how they lead NSOs to adopt PM practices in their internal environments. Because they receive resources from funding stakeholder, NSO are required to account for the resources that they receive through performance-based approaches (O'Boyle and Hassan, 2014; Winand et al., 2010). Pressure for accountability placed on NSOs by their stakeholders is an external influence that may lead to the adoption of PM practices. For instance, Perck et al. (2016) found that external influences led sport organisations to adopt professional organisational designs, while Papadimitriou (1998) found that the external environment influenced both the structure and behaviour of sport organisations with implications on their PM. Additionally, 
Slack and Hinings (1994) also noted changes to professional and bureaucratic structures of NSOs in response to pressure from state agency. Therefore, external environmental influences lead to changes in the internal environment of the NSO with implications on PM. Notwithstanding, there is a further need to establish how individuals within NSOs react to external influences by facilitating changes to their internal environments, and how the changes they make affect the PM of their NSOs. As such, the institutional work and contingency theories have been used in this study to explain the role that the individuals within the NSOs play to influence PM.

\section{Institutional work and contingency theories}

The concept of institutional work can be described as the practice of individuals and collective actors aimed at creating, maintaining and disrupting institutions (Lawrence et al., 2011). This concept is a more elaborate account of the institutional theory, and it describes the action of individuals within organisations that change because of isomorphism. It is important to note that institutions are created, sustained and reproduced by individuals through their daily activities in a variety of social setting (Edwards and Washington, 2015). Therefore, as much as organisations are affected by external influences, the individuals within the organisations are also affected by the same institutional pressures. Institutional work theory helps to explain the effort of individuals as they cope with, keep up with, tear down, transform or create new institutional structures within which they live, work, play and which gives them their roles, relationships, resources and routines (Lawrence et al., 2013). While the institutional work theory has been used in this study to describe how the individuals within NSOs work towards creating, maintaining or disrupting PM among NSOs, the contingency theory is used to elaborate on the contingency variables they are likely to use to respond to changes that happen to the NSO because of institutional pressures. 
The basic tenet of the contingency theory is that organisational effectiveness or organisational adaptation and survival can be achieved in more than one way (Thompson, 1967; Zeithaml, Varadarajan and Zeithaml, 1988). Organisational effectiveness depends on the appropriate matching of contingency factors with internal organisational designs that can allow appropriate responses to the environment (Zeithaml et al., 1988). Thompson (1967) perceived organisations as open systems that are faced with technological and environmental influences that result in changes to organisational structures, strategies and decision-making processes. According to Lawrence and Lorsch (1967) organisations should develop formal structures suited to their contexts, that will enable them to cope with environmental dynamics. While many contingency theory variables have been advanced over time (cf. Zeithaml et al., 1988), this theory becomes useful in this study to consider organisational processes that affect the PM of NSOs. As such, the institutional work and the contingency theories are used in this study to describe how individuals within NSOs respond to institutional pressures and use organisational processes such as leadership, communication and organisational climate to improve the efficiency and effectiveness of their mass participation and elite sport programs. Thereby creating, disrupting or maintaining PM as an institutional practice. In the next section, the methods that were used in this study are described.

\section{METHODS}

This study employs a literature review, conducted to; (1) explore the practice of PM as it exists among NSOs; (2) identify key elements that play a role in the PM of NSOs; (3) identify the components of a PM model; and (4) to develop a holistic model of PM for NSOs. As such, the literature review process was conducted in two parts. The first part of the literature review process was conducted to explore the practice of PM as it exists among 
NSOs and to identify key elements that play a role in the PM of NSOs. On the other hand, the second part of the literature review process was conducted to identify components of a PM model; and to develop a holistic model of PM for NSOs.

The first part of the literature review process started with an electronic search of databases including Google Scholar, Scopus and SPORTDiscus. Variations of search phrases that describe PM, organisational performance, organisational effectiveness and performance measurement among NSOs were used in this search. Articles that address PM as it exists among NSOs and the key elements that play a role in the PM of NSOs were identified. The literature search was limited to a period between 1986 and 2018 and articles that were selected were those that were published in English and addressed the organisational performance of NSOs. In this search, NSOs were viewed as organisations that administered sport to their members in their respective countries at national level. As such, articles that referred to the PM of sport organisations that did not operate at a national level in their countries such as sport clubs or government departments were not included in the first part of the literature review process. These articles were excluded from this process because organisations such as sport clubs or government departments have different organisational structures and design characteristics from those of NSOs. As such, they are managed differently and may implement their PM systems differently, hence these studies were not suitable to explain the practice of PM as it exists among NSOs and to identify key elements that play a role in the PM of NSOs. Furthermore, because this study aims to account for PM from a holistic perspective, studies that only addressed single performance dimensions within sport organisations were not included in the first part of the literature review. As such, a total of 15 articles were selected and reviewed to explore the practice of PM as it exists among NSOs and to identify key elements that play a role in the PM of NSOs. 
In the second part of the literature review process, an electronic search of databases including Google Scholar and Scopus using a variation of search phrases to describe PM models, components of a PM model and PM frameworks was conducted. The search was conducted to identify articles that address the identification of components of a PM model and the development of a holistic model of PM for NSOs. As a result, components of a PM model as proposed by Otley (1999) and Ferreira and Otley (2009) and PM models including the Balanced Scorecard (Kaplan and Norton, 1996; 2006), the Performance Prism (Neely, Adams and Crowe, 2001) and a model developed by Bayle and Robinson (2007) were identified from the literature and were studied to identify components of a PM model. The Balanced Scorecard was selected because it has been used by non-profit organisations, and in sport management research (Barajas and Sánchez-Fernández, 2009; Dimitropoulos et al., 2017). The Performance Prism was selected because it is a derivative of the balanced scorecard that proposes to offer operational improvements. And the model developed by Bayle and Robinson (2007) was selected because of its focus on sport organisations. Models such as the Total Quality Management (TQM), ISO 9001, Six-Sigma and lean manufacturing were not considered because of their orientation towards the PM of manufacturing organisations. Hence, these models were not suitable for the development of a holistic model of PM for NSOs because they are primarily non-profit organisations.

Further to identifying the components of a PM model that were required to develop a holistic model of PM of NSOs, it was important to consider the interdependence of the NSO's operating system. Therefore, NSOs were viewed as complex multilevel systems that required a multi-level approach to describe the link and interdependence between their operating environments (Chelladurai, 2017; Cunningham, 2012). To this end, the macro, meso and 
micro analytic framework was used in this study to describe the various levels of the organisations' operating environment (Miner, 2015; Tosi, 1992). The macro environment describes the external environment of NSOs as made up of external factors that influence their PM (Miner, 2015). As organisations that exist in a dynamic and ever-changing external environment, NSOs are affected by changes in the environment and their responses to these changes affect how they manage their organisational performance. Other external influences result from the NSOs relationships with stakeholders from the external environment. As such, the institutional, stakeholder and resource dependence theories are used in this study to provide a lens with which to consider the external environment of the NSO as the macro environment.

The meso environment describes the internal environment of the NSO and it is made up of organisational processes and activities and the stages of the PM process (Tosi, 1992; Miner, 2015). NSOs respond to external environmental influences by adapting their internal environment to deal with external influences that act on the NSOs. How the NSOs responses to external environmental influences impacts on their organisational performance. As such, the institutional and contingency theories are used in this study to explain changes to the internal environment of the NSO, made up of organisational processes and activities and the stages of the PM process as the meso environment (Tosi, 1992; Miner, 2015). The micro environment on the other hand comprises individuals within the NSO including the board and the operational staff (Tosi, 1992; Miner, 2015). They drive organisational processes and how they respond to the changes that happen to the NSO because of external influences, and how they adapt organisational processes and activities in response to external environmental changes impacts on organisational performance. As such the institutional work theory and the 
contingency theory are used explain the individuals within the NSO as the micro environment.

This multilevel approach helps to view the NSO from a holistic point of view, (Dixon and Bruening, 2007; Melton and Cunningham, 2014). This approach further provides an opportunity to consider how the various levels of the NSO are interdependent on one another and to explore how the strategic, operational and functional aspects of the NSO integrate for effective PM. Therefore, the macro, meso and micro analytic framework is used in this study to provide a rich description of the NSO's context that is necessary for developing an industry specific PM model (MacLean, 2016; Miner, 2015; Tosi, 1992). In the next section of this paper, the practice of PM as it exists among NSOs is discussed.

\section{THE PRACTICE OF PM AMONG NSOS}

A review of the 15 articles selected for this study revealed that organisational performance of NSOs has been studied over the last three decades (O'Boyle and Hassan, 2014; Solntsev and Osokin, 2018). However, much of the research focus has been directed towards performance measurement as opposed to PM (O’Boyle and Hassan, 2014). A variety of measurement approaches have been developed over time including the goal and system resources models, multiple constituency, multi-dimensional and the competing values approaches (cf. Bayle and Madella, 2002; Madella et al., 2005; Winand et al., 2010). While research of this nature has identified ways to measure organisational performance of NSOs, it does not address how these organisations manage their performance (O'Boyle and Hassan, 2014). Out of the 15 articles that were reviewed, 12 articles dealt with performance measurement, and only three (3) articles focused on PM. Most studies identified the dimensions of performance as illustrated in Table 1, (Bayle and Madella, 2002; Chelladurai et al., 1987; Madella et al., 
2005; Papadimitriou and Taylor, 2000; Shilbury and Moore, 2006; Winand et al., 2010; Solntsev and Osokin, 2018) and there was a consensus in most studies that PM was a multidimensional construct (Bayle and Madella, 2002; Chelladurai et al., 1987; Papadimitriou and Taylor, 2000; Winand et al., 2010).

\section{\{INSERT TABLE 1 HERE $\}$}

In their studies, Chelladurai et al. (1987) and Winand et al. (2014) indicate that PM relies on a systematic input, throughput, output and feedback cycle that yields organisational effectiveness, while studies by Chelladurai and Haggerty (1991), Papadimitriou and Taylor (2000), and Shilbury and Moore, (2006) emphasise the influence of stakeholders on the PM of NSOs. Additionally, other studies have identified factors that influence the PM of NSOs to include the institutional environment, (Frisby, 1986; Chelladurai et al., 1987; Madella et al., 2005; Papadimitriou, 1998) individuals within the NSOs (Papadimitriou and Taylor, 2000; Shilbury and Moore, 2006; Winand et al., 2011; Winand et al., 2013) and contingency variables such as structural design characteristics, (Frisby, 1986) and environmental conditions (Bayle and Robinson, 2007). With regards to PM, O’Boyle and Hassan (2015) established that the practice of PM among NSOs was still at evolutionary stages and that there was need for development in this regard. On the other hand, Bayle and Robinson (2007) developed a framework that NSOs could use to manage their performance. Bayle and Robinson's (2007) framework is discussed more elaborately in the PM models section of this paper.

In their study, O’Boyle and Hassan (2014) reviewed previous studies on organisational performance among NSOs and established the lack of PM studies conducted among NSOs. 
Therefore, there is a need for research to look beyond performance measurement and more towards establishing ways to effectively manage organisational performance of NSOs.

Further research on the PM of NSOs should employ holistic approaches to PM that integrate strategic, functional and operational aspects of organisational performance. Taking a holistic approach to analyse the PM of NSO allows for the inclusion of all elements that influence the PM systems from outside the organisation to its core. As such, the macro, meso and micro analytic framework serves this holistic approach as it divides the organisational environment into three focus areas that are discussed later. In the next section, the NSO's operating environment made up of the external and internal environmental influences is discussed.

\section{NSO'S OPERATING ENVIRONMENT}

\section{External environmental influences}

The external environment of the NSO is dynamic, and as it changes, it influences its operating environment (Menylk et al., 2013). Considering environmental pressures that influence the operating environment of NSOs, O'Boyle and Bradbury (2017) identified factors that include political, economic, socio-cultural, technological, environmental and legal factors (PESTEL). For instance, the political environment dictates the NSO's conformance to prescribed rules and regulations (Robinson, 2010). Economically, NSOs are affected by issues such as inflation and recession (Blakey, 2011). Technological advancements and innovations can improve the efficiency and effectiveness of the NSO's processes and capacities (Winand et al., 2013). On the other hand, socio-cultural factors influence the type of services that the NSOs offer to satisfy their stakeholders (O'Boyle and Bradbury, 2017). Furthermore, NSOs should comply with prescribed environmental restrictions and address industry specific legal issues such as doping and match fixing (Blakey, 2011; Robinson, 2010). Therefore, the influence of PESTEL factors on the operating 
environment of NSOs can influence the efficiency and effectiveness of organisational processes, and consequently PM.

Another external environmental factor that affects the operating environment of NSOs is the influence of stakeholders. The stakeholder and resource dependence theories provide a lens with which to describe the influence of NSO stakeholders as an external influence of PM. The NSOs' inability to generate sufficient resources for their operations and their dependence on external stakeholders (government, national sport agency, sponsors, media and community) to provide them, leads to pressure to satisfy stakeholders' interests (Vos et al., 2011; Wicker et al., 2012). This gives stakeholders the power to influence NSO decisions and processes (Wicker and Breuer, 2011). Furthermore, NSOs have multiple stakeholders with varying expectations. These include participation in decision making processes, creating international trade opportunities for governments, participating in sport programs and meeting new people for communities, visibility in the community for sponsors and selling newspaper stories for the media (Parent, 2008). To effectively manage their stakeholder interests, NSOs should reconcile the varying needs and expectations of their stakeholders and develop strategic plans and operational goals that aim to satisfy them all (Shilbury and Moore, 2006). Strategic plans and operational objectives have a direct influence on PM because they describe what an organisation wants to achieve (Ferreira and Otley, 2009). Therefore, the influence of the stakeholders in this regard demonstrates their influence on the PM of NSOs. Following the description above, external environmental factors that affect the PM of NSO include PESTEL factors and the influence of the external stakeholders. Therefore, PM models need to account for both PESTEL factors and the influence of the stakeholders because they impact on organisational processes with consequences on PM. Furthermore, there is a need to consider how the stakeholders as external influences facilitate 
changes to the internal environment of the NSOs with implication on PM. This is discussed next.

\section{Internal environmental influences}

The internal environment of the NSO comprises internal stakeholders, (clubs, teams and individual members) structural design characteristics, and organisational processes and activities. The structural design characteristics of NSOs influence their functions and their PM (Perck et al., 2016). NSO develop and adopt structural designs in response to influences from the external environment (Slack and Hinings, 1994; Papadimitriou, 1998; Perck et al., 2016). As such institutional isomorphism describes how external influences facilitates changes to internal environments of NSOs with implications to PM. Pugh et al. (1968) noted that as organisations grew, they developed patterns of structural designs that include specialisation, standardisation and centralisation. "Specialisation refers to the extent to which roles are differentiated within an organisation" while "standardisation refers to the existence of formalised procedures, rules and regulations that guide the activities of the organisation" (Kikulis et al., 1995: 81). Centralisation on the other hand refers "to the level at which decisions are taken and degree of involvement in decision making” (Kikulis, et al., 1995: 81). In their studies, Frisby (1985), Papadimitriou (1998) Slack and Hinnings (1994), and Perck, et al., (2016) found that in response to external influences, sport organisations adopted structural design characteristics that enabled them to perform better. Therefore, structural design characteristics play a role in the PM of NSOs and as such, PM models used by NSOs should account for structural designs that NSOs adopt when they respond to external influences. Another internal influence of PM involves the implementation of organisational processes including leadership, communication and organisational culture and activities that include mass participation and elite sports programs. Because these processes are 
implemented by individuals within NSOs, the institutional work and contingency theories are used to describe these processes and their implications to PM.

Leadership is the process by which a specific person or the leader influences a group of persons (subordinates) to achieve a common goal (Northhouse, 2010). Arnold et al. (2012) described the importance of leadership in PM and highlighted the need for NSO leaders to establish approaches that enhance effectiveness; understand the various NSO roles; develop NSO's contextual awareness; enhance personal skills and strengthen relationships among individuals (Arnold et al., 2012; Fletcher and Arnold, 2011). Effective leadership ensures the NSO's success in implementing PM. On the other hand, communication is the conveyance and receipt of information between the sender and the receiver, downwards as well as upwards, which contributes to the maintenance and improvement of the objectives of the organization. Ferreira and Otley (2009) have noted the importance of communication in implementing PM. They believe communicating with individuals within the NSO improves their understanding of the strategy and its implementation thereby improving PM (Ferreira and Otley, 2009).

Organisational climate is the unique personality of an organisation comprising of attitudes and beliefs that influence individual's collective behaviour (Borucki and Burke, 1999). Additionally, organisational culture includes the shared values, norms and behaviours of an organisation (Borucki and Burke, 1999). Therefore, organisational climate and culture affect PM because the NSO's personality and the shared norms, and the values and behaviour of individuals determines the extent of their efforts to attain its goals and objectives. The importance of organisational climate and culture was highlighted by Bayle and Robinson, 
(2007) who noted that NSOs should provide an enabling environment and a participatory culture that ensures the performance of all members.

Therefore, it is important for a PM model for NSOs to account for organisational processes that include leadership, communication and organisational climate and culture, and how these processes are used to implement mass participation and elite sport programs activities. The utility of institutional work and the contingency theories in identifying internal environmental factors cannot be understated. Moreover, these theories are also used to consider how the individual within NSOs influence PM. This is discussed next.

\section{Individuals within the NSO and PM}

Individuals within the NSO include the board and the operational staff. NSO board members are volunteers who govern NSOs by ensuring adherence to organisational best practice and formulating strategies that offer direction to organisational processes and activities (Hoye and Cuskelly, 2003; Shilbury and Ferkins, 2011). According to UK Sport (2004) the roles of NSO board members include setting strategic aims, providing leadership that puts the aims into effect, supervising management and reporting to members. In their study, Hoye and Doherty (2011) noted that the performance of the board contributed to the overall performance of the NSO (Hoye and Doherty, 2011). Interestingly however, Hoye (2007) noted the difficulties of evaluating the performance of individual board members because of the voluntary nature of their roles. Therefore, because of the contribution that board performance makes to the overall performance of NSOs, there is a need for the holistic model of PM for NSOs to account for the role that the board members play. 
The operational staff of the NSO are the paid employees and operational volunteers that are responsible for implementing the organisational processes. Paid employees are professionals employed by NSO to render their professional services, and they are remunerated. Operational volunteers are individuals who render services to the NSO and receive little or nothing in the way of personal financial remuneration for their time, effort and impact (Doherty and Carron, 2003). While the operational staff play the important role of implementing organisational processes and activities, research into their performance and their contribution to PM is lacking. However, in their study, Hoye and Cuskelly (2003) found that the performance of the board was enhanced in situations where leadership was shared, and there was mutual trust between the board and management. They further found that the control of information between the board and the operational staff affected board performance (Hoye and Cuskelly, 2003). Therefore, NSO board and the operational staff members should aim to facilitate an interdependent relationship that is subject to ongoing negotiation because, how they work together influences organisational performance (Hoye and Cuskelly, 2003). Good relationships between the board and the operational staff facilitate a good organisational climate that fosters organisational performance (Borucki and Burke, 1999). As such, it is important for the individuals within the NSO to ensure that they work to make their environment enabling for the successful implementation of PM. Therefore, a holistic model of PM for NSOs should account for the role that individuals within the NSO play, because they have the capacity to create, disrupt and maintain organisational processes that affect PM. Furthermore, how they implement organisational processes and use contingency variables to respond to external and internal environmental influences impacts on their PM. 
The NSOs external and internal environment and the individuals within the NSO play key roles in the PM of NSOs. However, to develop a holistic model of PM for NSOs, there is need to identify components of a PM model from literature. In the next section, PM models are discussed, and their components described.

\section{PERFORMANCE MANAGEMENT MODELS}

PM models describe how organisations attain their mission by aligning their strategies with their processes and capabilities, and continuously monitoring and evaluating the process to facilitate learning for future improvements (Biticti et al., 1997). They are essentially management control systems that use measures to establish the quality and efficiency of organisational processes. One popular PM model the Balanced Scorecard was developed by Kaplan and Norton (1996) and is widely adopted and used by different organisations. The Balanced Scorecard enables organisations to manage their strategies, by linking their objectives, initiatives and performance measurement at all levels of the organisation (Kaplan and Norton, 1996; 2006). This PM model allows managers to view organisations from four perspectives that include customer, financial, internal business and innovation and learning perspectives (Kaplan and Norton, 1996). The customer perspective measures how an organisation ensures the satisfaction of their customers by creating value them, while the internal business perspective measures the efficiency of business processes and competencies (Kaplan and Norton, 2006). The innovation and learning perspective focusses on organisational growth by identifying what was learned from previous PM cycles and ways to change and improve, while the financial perspective deals with financial issues such as profit, growth, risk and shareholder value (Kaplan and Norton, 2006). Managers use both qualitative and quantitative approaches to measure organisational performance according to these four perspectives, and when this happens, the scorecard is balanced (Kaplan and Norton, 2006). 
While many organisations have adopted the Balanced Scorecard to manage their performance, Robinson (2010) has highlighted challenges that could arise from using this model among sport organisations. These include conflicting measures, managers not reacting to the feedback from the performance measurement process and lack of skills to interpret the information that the Balanced Scorecard generates (Robinson, 2010). Furthermore, Neely et al. (2001) criticized the use of first generation PM models such as the Balanced Scorecard, because they believed that they inundated managers with measurements, and there was a need to focus more effort towards PM. To address this, they developed a derivative of the Balanced Scorecard called the Performance Prism that focuses on stakeholder management and comprises stakeholder satisfaction, stakeholder contribution, strategies, processes and capabilities as illustrated in Table 2 (Neely et al., 2001).

\section{\{INSERT TABLE 2 HERE $\}$}

In sport management literature, Bayle and Robinson (2007) developed a model that comprise strategic performance mix and operational performance mix. The strategic performance mix includes factors that determine the NSOs' strategic focus while the operational performance mix focuses on factors that impact on its operation (Bayle and Robinson, 2007). Strategic mix factors include the system of governance, the quality of the operating framework and the position of the NSO system within the industry of its sport (Bayle and Robinson, 2007). The operational performance mix on the other hand is made up of factors that facilitate or inhibit organisational performance. Bayle and Robinson (2007) identified facilitators of performance to include forms of level of professionalisation, presence of a participatory organisational culture and adopting a participatory culture to performance. On the other hand, inhibitors of 
performance included: deficient information system, inappropriate incentive mechanisms, absence of control mechanisms and political sclerosis. Bayle and Robinson's (2007) model demonstrates the importance of the strategic focus and the operating environment of the NSO in PM. This model shows how NSOs interpret their strategies and how they use their operating environments to facilitate their achievement. This model however, does not illustrate the cyclic nature of the PM process which relies on the feedback and feedforward loops to facilitate future improvements. Furthermore, while the model identifies the quality of the operating framework and the position of the NSO system within the industry of its sport, it does not show how the external environment influence PM of NSO.

To develop a PM model, Otley (1999) and Ferreira and Otley (2009) illustrate the importance of a mission and vision for providing direction of what the organisation wants to achieve and the importance of communicating it to the manager and employees. They further highlight the importance of the key success factors, the organisation's structural design, strategies, plans, key performance measures, and targets and how they are communicated to the manager and employees of the organisation. Otley (1999) and Ferreira and Otley (2009) further highlight the importance of performance measurement, rewards, penalties and the feedback, feedforward loops, and their uses for learning. They also consider the influence of the external environment and the interdependence of the organisation's operating system. These issues are illustrated in Table 2.

The Balanced Scorecard, the Performance Prism, the Bayle and Robinson's (2007) model and the issues raised by Ferreira and Otley (2009), describe what constitutes a PM model. It is made up of actions directed towards satisfying stakeholders, that account for the environment, and align organisational activities and processes with the mission and vision of 
the organisation. Furthermore, there should be continuous monitoring and evaluation of the organisation's process and activities through measurement, and the results reported and used to facilitate future improvements. Insights gained on the components of a PM model were used to develop the holistic model for PM of NSOs. Furthermore, highlights from the literature review indicate the importance of the holistic model of PM for NSOs to account for PESTEL factors and the influence of the stakeholders. Furthermore, the model should consider the organisational design characteristics, processes that include leadership, communication and organisational culture and activities that include mass participation and elite sports programs. A holistic model of PM for NSOs that accounts for these factors was developed and is presented in the next section.

\section{A HOLISTIC MODEL OF PM FOR NSO}

Figure 1 illustrates the holistic model of PM for NSOs and its description follows in the next section.

[Insert figure 1 here]

\section{Macro environment}

A holistic model of PM for NSOs accounts for the external environmental influences (Ferreira and Otley, 2009). The assumption is that a change in the external environment of the NSO stimulates a change in the organisational strategy and other organisational processes including PM (Melnyk et al., 2013). The model illustrates PESTEL factors and external stakeholders as part of the macro environment. The interaction between the external stakeholders and the NSO as presented in the model is through consultation and communication. Consultation entails information sharing between external stakeholder and 
the NSO on the resources made available and the expectations to be met in return. The external stakeholders' expectations are used to formulate objectives that NSO aim to achieve to guarantee high stakeholder satisfaction (Parent, 2008; Wellens and Jegers, 2014). Communication on the other hand entails information sharing at the end of the performance measurement process. It details feedback on the extent to which stakeholders' expectations are met and how the NSO will improve in the future. The information sharing between the NSO and the external stakeholders through consultation and communication is important for the maintenance of the PM process (Ferreira and Otley, 2009). The marco environmental factors as illustrated in the model influence the internal functions and operations of the NSO and their ability to respond to these, influences their PM (Melnyk et al., 2013).

\section{Meso environment}

The meso environment is the internal environment of the NSO. It is made up of the internal processes and the four stages of the PM process that include PM 1: Organisational goals and objectives, PM 2: Processes and activities, PM 3: Performance measurement and PM 4: Feedback and feedforward. The NSO's clubs, teams and individual members affiliated to it expect NSO to organise mass participation and elite sport programs (Winand et al., 2010). They meet in general assemblies to draw their strategic plans, elect board members to implement and appraise their plans, and to agree on improvements. Their involvement in the NSO's strategic planning ensures their influence on developing goals and objectives that are based on their expectations (Parent, 2008; Parent et al., 2015). They are also appraised on the results of the PM process through the feedback and feedforward and the information shared is then used to improve the NSO strategic plans (Ferreira and Otley, 2009). 
PM 1: Organisational goals and objectives: This is the first stage of the PM process. When formulating organisational goals and objectives, there should be a consideration for the resources available and the structural design characteristics of the NSO (Papadimitrou, 1998; Perck et al., 2016). The PM 1 stage is made up of performance objectives, performance dimensions, key performance indicators and performance targets. NSO's goals and objectives are used to draw performance objectives. The performance objectives are then used to set the key performance indicators which describe what the NSO wants to achieve in a quantifiable manner. Then the targets are set to prioritise performance objectives and draw a realistic picture of the goals and objectives that the NSO intends to achieve. Performance targets are used to measure performance. Otley and Ferreira (2009) stress the importance of disseminating the NSO's goals and objectives to the individuals within the NSO to ensure that they have a common understanding of intended performance achievements.

PM 2: This stage of the PM process considers organisational processes and activities. Organisational processes include effective leadership (Arnold et al., 2012; Fletcher and Arnold, 2011) communication (Ferreira and Otley, 2009) and fostering an organisational climate and culture that facilitates performance (Bayle and Robinson, 2007). And activities include mass participation and elite sport programs (Winand et al., 2010). There should be an alignment of the goals and objectives set in stage one with organisational processes and activities to ensure better performance (Kaplan and Norton, 2006).

PM 3: This is the performance measurement stage that entails establishing the extent of efficiency and effectiveness in the attainment of goals and objectives of the NSO. It involves comparing the overall performance achieved against the set performance targets. The comparison of the actual performance against the performance targets gives a measure of 
NSO performance achieved. In this stage NSOs should employ measurement procedures that give feedback on the efficiency of organisational processes and the satisfaction of the stakeholders. This stage is important because it evaluates the PM process and it provides information that is used for its maintenance (Biticti et al., 1997).

PM 4: This stage of the PM process includes feedback and the feedforward (Ferreira and Otley, 2009). The feedback is used to inform external and internal stakeholders on how their expectations were met. And, the feedforward is used for learning on ways to improve future performance cycles. This learning curve is used to facilitates changes to the organisational structural designs and improvements to the vision and mission of the NSO. The learning curve also provides information on the amount and type of resources required for future performance cycles.

\section{Micro environment}

The micro environment comprises of the board and the operational staff of the NSO and they are responsible for driving organisational processes and activities. Their interpretation of the NSO's environments influences how PM is implemented. The board and the operational staff interpret the NSO's vision, mission, goals and objectives and use resources available through the structural design characteristics and organisational processes to implement the mass participation and elite sport programs. They also facilitate performance measurement through periodic assessments, summative assessment, peer assessments and self-assessment. Furthermore, they make performance measurement results available for sharing with NSO stakeholders and use the information to facilitate learning for future cycles. The NSO board should use their competencies to offer strategic direction to the operational staff, and they 
should foster a relationship that facilitates a good working environment that improves the attainment of organisational goals and objectives (Hoye and Cuskelly, 2003).

\section{DISCUSSION}

\section{Macro environment}

The external environment is dynamic, and it evolves and changes with time (Ferreira and Otley, 2009; Melnyk et al., 2013). The NSO has no control over changes in the external environment such as changes in the political environment, economic climate, technological advancements, environmental influences, socio-cultural influences as well as legal issues (PESTEL). However, their ability to respond to changes in their external environment by adapting their internal environments to the changes, improves the efficiency and effectiveness of their organisational processes and their PM (Ferreira and Otley, 2009). There has been no evidence that shows a direct association between the external environmental influences and PM (Perck et al., 2016). Therefore, this calls for further studies to investigate how NSOs respond to the influence of PESTEL factors specifically considering how they adapt by changing their internal environments and establishing the associated impacts on PM. Furthermore, this research could establish if PESTEL factors influence changes to the implementation of the various stages of the PM process including goal and objective setting, organisational processes and activities, performance measurement and feedback and feedforward and the extent of their influence and how the influences if any affect the development and use of PMS among NSO. This research could provide the link between the external environment and PM, specifically how influences such as government regulations, economic climate, technological advancements, environmental legislation, socio-cultural and legal issues affect PM processes in the unique context of the NSO. 
The expectations of external stakeholders add to the external environmental influences that affects PM of NSOs. The resource vulnerabilities of NSOs lead them to form resources dependent relationships with funding stakeholders, and they place demands on the NSOs to meet their needs and expectations, thereby, influencing their strategic goals and objectives (Papadimitriou and Taylor, 2000; Parent et al., 2015; Winand et al., 2010). An influence on the strategic goals and objectives of an organisation has implications on its PM. As such, further research could establish how funding stakeholders influence the development and use of PMS among NSOs. This type of research could use the stakeholder, resource dependence and institutional theories to provide insights into how the expectations of the funding stakeholders affect organisational processes including the PM process.

The stakeholder theory could be used to identify and categorise stakeholders according to the roles they play in NSOs. For instance, Mitchell et al. (1997)'s power, legitimacy and urgency framework could be used to classify NSO stakeholders according to their salience. This framework could be used to further establish how the different categories of stakeholder according to their salience influence the development and use of PMS among NSOs. The resource dependence theory could also be used to study the power relationship between the NSO and their funding stakeholders. This theory could help to provide understanding into how NSO's resource vulnerabilities lead them to conform to the needs and expectations of the funding stakeholders and whether that leads them to use performance-based approaches to account for the resources used. Furthermore, the theory could help to analyse how NSOs with different resources dependencies towards their funders may be affected differently when organisational goals and objectives are set. Because NSO receive resources from many funders, this research could establish the association between the amount and type of resources that they receive and the goals and objectives that they set. The institutional theory can also be used in 
this line of research, to study how NSOs are affected by coercive, mimetic and normative pressures to adopt PM as an institutional practice. Because NSOs receive resource from funding stakeholders and are expected to account through performance-based approaches, (O’Boyle and Hassan, 2014) this type of research could establish whether funding stakeholders use coercive influences on NSOs to account, or whether NSOs copy how other organisations or whether NSOs are influenced by professionals working within them to account through performance-based approaches. This research could provide insights into whether PM has been legitimised as an institutional practice by NSOs, which are primarily non-profit organisations governed by volunteers. The study could be useful as it offers understanding into how NSO develop and use PMS in their unique operating contexts. The use of these organisational theories in unison could provide a rich understanding of the context of the NSOs and how their external environmental pressures such as the influence of the needs and expectations of stakeholders affects their goal and objectives setting and their overall PM process. This will provide an understanding of the influence of external stakeholders on the PM of NSO.

In response to macro environmental influences, or external pressures such as PESTEL factors or the influence of external stakeholders, NSOs adapt by changing their operating environment or their meso environment to survive and perform better. The changes to the operating environment of NSOs are facilitated by the individuals within the NSO including the board and the operational staff who make up the micro environment of the NSO. This shows the link and interdependence between the NSOs' macro, meso and micro environments. In that changes in one environment necessitates changes in other environments to accommodate that change, with implications on PM. The meso environment which is mainly the internal environment of the NSO made up of its operating system and the stages of the PM process is discussed next. 


\section{Meso environments}

NSO have clubs, teams and individual members affiliated to them. These members require NSOs to facilitate quality mass participation and elite sport programs for them, and they influence the goals and objectives set by the NSO (Papadimitriou and Taylor, 2000; Parent $e t$ $a l ., 2015)$. Considering the influence of external and internal stakeholders on the formulation of NSOs' goal and objectives, further research could establish how they prioritise their objectives to meet the varying needs and expectations of their stakeholders. Shilbury and Moore (2006) pointed to conflicting needs and expectations of the various NSO stakeholders and the need to reconcile them by developing strategic plans that cater for all stakeholders. However, with their varying degrees of influence on the goals and objectives setting of NSOs, it could be interesting to study how the NSOs deal with the conflicting needs and expectations of their stakeholders. Therefore, further research could establish how the conflicting needs and expectations of their stakeholders affect the goals and objectives set by NSOs and how that affects other stages of the PM process.

The NSO structural design characteristics including specialisation, standardisation and centralisation influence the efficiency and effectiveness of its organisational processes when implementing mass participation and elite sport programs (Frisby, 1985; Kikulis et al., 1995; Thibault et al., 1991). The model of PM for NSO highlights the importance of organisational processes such as leadership (Arnold et al., 2012; Fletcher and Arnold, 2011), communication (Ferreira and Otley, 2009) and organisational culture (Bayle and Robinson, 2007; Borucki and Burke, 1999; Bowen and Ostroff, 2004) in a PM process. How NSO are structured (specialisation, standardisation and centralisation), influences how they implement organisational processes (leadership, communication and organisational climate and culture), and this impacts on the quality of their activities (mass participation and elite sport programs) 
and affects how they manage their performance. NSO are governed by volunteer board members therefore, their implementation of organisational processes such as leadership, communication and organisational climate and culture may be different. Therefore, further research that employs the contingency theory could consider how the structural arrangements of NSOs impact on organisational processes and how it affects the implementation of NSO activities and the consequences on PM. Specifically how the individuals within NSOs implement organisational processes through the NSO's structural arrangements and the implications of their actions on PM of NSOs. Furthermore, research that uses the contingency theory could further uncover how volunteer boards facilitate leadership in the unique setting of the NSO, and how their leadership processes impact the implementation of their elite sport and mass participation programs and other stages of the PM process (goal and objective setting, performance measurement and feedback and feedforward).

The importance of an organisational culture that facilitates PM has been highlighted by Bayle and Robinson (2007). When individuals within the NSO have shared norms, beliefs and attitudes towards PM, the NSO may manage its performance better. However, not much research has been conducted on the influence of organisational culture on the PM of NSO. This calls for more research in this area, to establish how organisational culture made up of the shared norms values and beliefs of the board and operational staff of NSO impacts on the various stages of the PM process (goal and objective setting, organisational processes and activities, performance measurement and feedback and feedforward).

The relationship between the volunteer boards and the operational staff of the NSO has been studied in sport management literature (Hoye and Cuskelly, 2003), however the influence of this relationships on creating an enabling environment that foster PM has not been studied. 
Research into the influence of organisational climate on PM of NSO could consider the influence of the relationship between the board members and the members of the operational staff. This could offer insights into how the shared values, belief and norms of the board and operational staff of NSO foster an organisational culture that facilitate PM. Communication is important as it facilitates a common understanding of what the NSO intends to archive in terms of its PM strategy (Ferreira and Otley, 2009). Future research that employs could establish how communication is implemented among NSO, accounting for its uniqueness. It could be interesting to establish how the volunteer boards communicate with the operational staff on the strategic direction of the NSO and how it impacts on the various stages of the PM process.

There has been research on the measurement of the performance of NSO with emphasis on developing measurement tools that account for the uniqueness of NSO (O'Boyle and Hassan, 2014). However, research does not show how NSO use the information obtained from the performance measurement process. The model of PM for NSO highlights the importance of performance measurement and how its information is used to facilitate feedback and feedforward loops that are used as a learning process to inform future PM cycles. Therefore, future research could consider how NSO use the information from their performance measurement processes and establish how they learn from it as well as the how they facilitate improvements to future PM cycles. While efficiency and effectiveness of organisational processes are important to the PM of NSOs, it is the individuals within the NSO who drive the organisational processes. The role that they play as illustrated by the holistic model of PM for NSOs is discussed next.

\section{Micro environment}


The PM model for NSO highlights the roles of the board and the operational staff on the PM of NSOs. The importance of board members, their competencies and their overall performance has been highlighted in the model. This issue has been studied in sport management literature (Ferkins and Shilbury, 2010; Fletcher and Arnold, 2011; Hoye, 2007; Hoye and Cuskelly, 2003; Hoye and Doherty, 2011; McDonald and Sherry, 2010). However, McDonald and Sherry (2010) have noted that there was little empirical evidence to support the contention that there is a positive relationship between the performance of the board and organisational performance. Therefore, further research could establish how NSO measure board performance in relation to its contribution to organisational performance. The model illustrates that one of the components of measuring performance is through employee appraisals that establish the extent to which employees are successful in attaining their set performance objectives. This is an important exercise because the performance of the operational staff may contribute to the overall PM of the NSO. Therefore, further research could establish how the operational staff of NSOs facilitate their self and peer appraisals and whether the performance of volunteers is appraised and how it is appraised. As well as to establish how the performance of the operational staff contributes to the overall performance of the NSO. This research could offer insights into how NSO manage the performance of their workforce which comprises of a mix between volunteers and paid staff.

The holistic model of PM for NSO illustrates the role of the individuals within the NSO and their interaction with the various organisational processes and the stages of the PM process. Their role is to interpret the external and internal environments and work towards creating, maintaining or even disrupting PM as an institutional process in their NSO (Lawrence et al., 2011). Furthermore, as individuals within NSOs interpret their external and internal environments, they employ contingency variables that enable their organisations to survive 
and performance better. As such, the contingency and institutional work theories can be used to study how the individuals within the NSO interpret changes to the external environment and how they adapt by facilitating internal environmental changes. The institutional work theory can be used to establish how individuals within NSOs work to create, maintain or disrupt PM as an institutional practice within NSOs in response to changes in the external environment. And the contingency theory could be used to identify and describe contingency variables that individuals within the NSO implement in response to changes in the external environment. This perspective has not been studied in literature and it could offer insights into the role that the individuals within the NSOs play to establish PM as an institutional practice. While the holistic model of PM highlights avenues for further research, it also has practical utilities, and these are discussed next.

The model of PM for NSOs provides information to sport managers on the interdependence of the NSO's macro, meso and micro environments and further demonstrates how changes in one environment necessitates changes in other environments. This can help them to develop intuitions on how to respond and adapt their operating environments, to ensure the survival and better performance of their NSOs. The model also provides information on the external and internal factors that influence the PM of NSOs. While sport managers do not have control over the external factors that influence PM of NSOs, knowledge of these influences prepares them for more appropriate responses. Furthermore, knowledge of external influences of PM provides sport managers with avenues to control their environments in ways that will ensure that their NSOs perform better. The model further provides a description of the PM process and how it can be used to improve organisational processes. This model can be seen as a practical tool allowing sport managers to identify key elements that play a role in the management of their performance. Therefore, sport managers can effectively use the PM 
process as outlined in the model to improve the efficiency and effectiveness of their processes. Because the model accounts for the uniqueness of NSOs, it provides specific information that is useful to sport managers.

\section{CONCLUSION}

This paper intended to conceptualise PM from a holistic point of view and to develop a holistic model of PM for NSOs from a literature review process. The study was underpinned by organisational theories that include stakeholder, resource dependence, institutional, institutional and contingency work theories. The study further used the macro, meso and micro multi-level approach to describe the PM of NSOs from a holistic perspective and to describe the interdependence its operating system. The holistic model of PM for NSO identifies external and internal environmental influences and the roles they play in the NSO's PM process. The model further highlights the NSO's organisational processes and activities and the stages of the PM process and proposes avenues for further research into the PM of NSO.

This study contributes to knowledge in that it provides a framework for the discussion of PM among NSOs. Previous studies that have been undertaken in the organisational performance of NSOs have focused on performance measurement rather than performance management. This study provides a framework with which PM of NSOs can be considered from a holistic point of view accounting for the unique context of NSOs, the interdependence of their operating system and their relationship with their environment. This study provides an avenue for NSOs to consider the implementation of holistic approaches to PM that will ensure their efficiency and effectiveness in their ever-competitive environments where they are required to compete for resources with other non-profit organisations. Furthermore, this 
study considers the cyclic nature of the process and the stages of the PM process that include among others, the feedback, feedforward and the learning curve stages that provide an opportunity to foster dynamism and new ideas into the system that improve the effectiveness of NSOs. This study also contributes to knowledge as it proposes avenues for further research into holistic perspectives towards organisational performance of NSOs.

While this study contributes to sport management literature and has practical utilities, it is important to note the limitation, that it was developed purely from a literature review exercise. As such, there is a need for the holistic model of PM for NSOs to be developed further and improved through further research and empirical testing. 


\section{References}

Arnold, R., Fletcher, D. and Molyneux, L. (2012), Performance leadership and management in elite sport: recommendations, advice and suggestions from national performance directors, European Sport Management Quarterly, Vol. 12 No. 4, pp. 317-336.

Barajas, A. and Sánchez-Fernández, P. (2009), The balanced scorecard of public investment in sport: proposal for change, Rivista di Diritto ed Economia dello Sport, Vol. 5 No. 1, pp. 89-107.

Bayle, E. (2005), Institutional changes and transformations in an organisational field: the case of the public/private 'model of French sport, International Journal of Public Policy, Vol. 1 No. 1-2, pp. 185-211.

Bayle, E. and Madella, A. (2002), Development of a taxonomy of performance for national sport organizations, European Journal of Sport Science, Vol. 2 No. 2, pp. 1-21.

Bayle, E. and Robinson, L. (2007), A framework for understanding the performance of national governing bodies of sport, European Sport Management Quarterly, Vol. 7 No. 3, pp. 249-268.

Bititci, U.S., Carrie, A.S. and McDevitt, L, (1997), Integrated performance measurement systems: a development guide, International Journal of Operations \& Production Management, Vol. 17 No. 5, pp. 522-534.

Blakey, P. (2011). Sport marketing, Learning Matters, Exeter.

Borucki, C.C. and Burke, M.J. (1999), An examination of service-related antecedents to retail store performance, Journal of Organizational Behavior, Vol. 20, pp. 943-962.

Bowen, D.E. and Ostroff, C. (2004), Understanding HRM-firm performance linkages: The role of the "strength" of the HRM system, Academy of Management Review, Vol. 29 No. 2, pp. 203-221. 
Byers, T., Slack, T. and Parent, M. (2012), Key Concepts in Sport Management, Sage, London.

Chelladurai, P. (2017). Managing organizations for sport and physical activity: A systems perspective, (4th ed.), Routledge, Oxon.

Chelladurai, P. and Haggerty, T. R. (1991). Measures of organizational effectiveness of Canadian national sport organizations. Canadian journal of sport sciences. Vol. 16 No 2, pp.126-133.

Chelladurai, P., Szyszlo, M., and Haggerty, T. R. (1987). Systems-based dimensions of effectiveness-the case of national sport organizations. Canadian Journal of Sport Sciences-Revue Canadienne des Sciences du Sport. Vol 12 No 2, pp 111-119.

Cunningham, G. (2012), A multilevel model for understanding the experiences of LGBT sport participants, Journal for the Study of Sports and Athletes in Education, Vol. 6 No 1, pp. 5-20.

DiMaggio, P. and Powell, W.W. (1983), The iron cage revisited: Collective rationality and institutional isomorphism in organizational fields, American Sociological Review, Vol 48 No 2, pp. 147-160.

Dimitropoulos, P., Kosmas, I. and Douvis, I. (2017), Implementing the balanced scorecard in a local government sport organization: Evidence from Greece, International Journal of Productivity and Performance Management, Vol. 66 No. 3, pp. 362-379.

Dixon, M. A. and Bruening, J. E. (2007), Work-family conflict in coaching I: A top-down perspective, Journal of Sport Management, Vol 21 No 3, pp. 377-406.

Doherty, A.J. and Carron, A.V. (2003), Cohesion in volunteer sport executive committees, Journal of Sport Management, Vol. 17 No. 2, pp. 116-141. 
Edwards, J.R. and Washington, M. (2015), Establishing a "safety net": Exploring the emergence and maintenance of College Hockey Inc. and NCAA Division I Hockey, Journal of Sport Management, Vol. 29 No. 3, pp. 291-304.

Ferkins, L. and Shilbury, D. (2010), Developing board strategic capability in sport organisations: The national-regional governing relationship, Sport Management Review, Vol. 13 No. 3, pp. 235-254.

Ferreira, A. and Otley, D. (2009), The design and use of performance management systems: An extended framework for analysis, Management Accounting Research, Vol. 20 No. 4, pp. 263-282.

Fletcher, D. and Arnold, R. (2011), A qualitative study of performance leadership and management in elite sport, Journal of Applied Sport Psychology, Vol. 23 No. 2, pp. 223-242.

Freeman, R.E. (1984), Strategic Management: A Stakeholder Approach, Pitman, Boston, MA.

Frisby, W. (1985), A conceptual framework for measuring the organizational structure and context of voluntary leisure service organizations, Loisir et Société/Society and Leisure, Vol. 8 No. 2, pp. 605-613.

Frisby, W. (1986). Measuring the organizational effectiveness of national sport governing bodies. Canadian Journal of Applied Sport Sciences. Vol 11 No 2, pp 94-99.

Hoye, R. (2007). Commitment, involvement and performance of voluntary sport organization board members, European Sport Management Quarterly, Vol. 7 No. 1, pp. 109-121.

Hoye, R. and Cuskelly, G. (2003), Board-executive relationships within voluntary sport organisations, Sport Management Review, Vol. 6 No. 1, pp. 53-73.

Hoye, R. and Doherty, A. (2011), Non-profit sport board performance: A review and directions for the future, Journal of Sport Management, Vol. 25 No. 3, pp. 272-285. 
Kaplan, R.S. and Norton, D.P. (2006), Alignment: Using the Balanced Scorecard to create Corporate Synergies, Harvard Business School Publishing Corporation, Boston.

Kaplan, R.S. and Norton, D.P. (1996), The Balanced Scorecard: Translating Strategy into Action, Harvard Business School Press, Boston.

Kikulis, L.M., Slack, T. and Hinings, C.R. (1995), Sector-specific patterns of organizational design change, Journal of Management Studies, Vol. 32 No. 1, pp. 67-100.

Lawrence, T.B., Leca, B. and Zilber, T.B. (2013), Institutional work: Current research, new directions and overlooked issues, Organization Studies, Vol. 34 No. 8, pp. 1023-1033.

Lawrence, P. R., and Lorsch, J. W. (1967). Organisation and environment: Managing differentiation and integration. Boston: Harvard Business School.

Lawrence, T., Suddaby, R., and Leca, B. (2011), Institutional work: Refocusing institutional studies of organization, Journal of Management Inquiry, Vol. 20 No. 1, pp. 52-58.

MacLean, J. (2016), 'Performance Management' in Hoye, R. and Parent, M.M. (Eds.), The Sage Handbook of Sport Management, Sage Publications, London, pp.160 - 180

Madella, A., Bayle, E. and Tome, J. (2005), The organisational performance of national swimming federations in Mediterranean countries: A comparative approach, European Journal of Sport Science, Vol 5. No. 4, pp. 207-220.

McDonald, H. and Sherry, E. (2010), Evaluating sport club board performance: A customer perspective, Journal of Sport Management, Vol. 24 No. 5, pp. 524-543.

Melnyk, S.A., Bititci, U., Platts, K., Tobias, J. and Andersen, B. (2014), Is performance measurement and management fit for the future? Management Accounting Research, Vol. 25 No. 2, pp. 173-186.

Melton, E.N. and Cunningham, G.B. (2014), Who are the champions? Using a multilevel model to examine perceptions of employee support for LGBT inclusion in sport organizations, Journal of Sport Management, Vol 28 No 2, pp.189-206. 
Miner, J. B. (2015). Organizational behavior 1: Essential theories of motivation and leadership. New York. Routledge.

Mitchell, R.K., Agle, B.R. and Wood, D.J. (1997), Toward a theory of stakeholder identification and salience: Defining the principle of who and what really counts. Academy of Management Review, Vol 22 Vol 4, pp. 853-886.

Morgan, G. (2007) Images of organization, Thousand Oaks: Sage

Neely, A., Adams, C. and Crowe, P. (2001), The performance prism in practice. Measuring Business Excellence, Vol. 5 No. 2, pp. 6-13.

Northouse, P.G. (2010). Leadership: Theory and Practice (5th ed.). Sage Publication. London

Nowy, T., Wicker, P., Feiler, S. and Breuer, C. (2015), Organizational performance of nonprofit and for-profit sport organizations. European Sport Management Quarterly, Vol. 15 No. 2, pp. 155-175.

O'Boyle, I. and Bradbury, T. (2017), The new sport management environment. in Bradbury, T and O’Boyle, I (Eds.), Understanding Sport Management, Routledge, London, pp. 21-28.

O’Boyle, I. and Hassan, D. (2014), Performance management and measurement in nationallevel non-profit sport organisations, European Sport Management Quarterly, Vol. 14 No. 3, pp. 299-314.

O'Boyle, I., and Hassan, D. (2015). Applying Performance Management Practices within Non-Profit Sport Organisations: A Case Study of New Zealand. International Journal of Sport Management. Vol 16, pp 1-24.

Otley, D. (1999), Performance management: a framework for management control systems research, Management Accounting Research, Vol. 10 No. 4, pp. 363-382. 
Papadimitriou, D. (1998), The impact of institutionalized resources, rules and practices on the performance of non-profit sport organizations, Managing Leisure, Vol. 3 No. 4, pp. 169-180.

Papadimitriou, D. (2007), Conceptualizing effectiveness in a non-profit organizational environment: An exploratory study, International Journal of Public Sector Management, Vol. 20 No. 7, pp. 571-587.

Papadimitriou, D. and Taylor, P. (2000), Organisational effectiveness of Hellenic national sports organisations: A multiple constituency approach, Sport Management Review, Vol. 3 No. 1, pp. 23-46.

Parent, M.M. (2008), Evolution and issue patterns for major-sport-event organizing committees and their stakeholders, Journal of Sport Management, Vol. 22 No. 2, pp. 135-164.

Parent, M.M., Kristiansen, E., Skille, E.Å. and Hanstad, D.V. (2015), The sustainability of the Youth Olympic Games: Stakeholder networks and institutional perspectives, International Review for the Sociology of Sport, Vol. 50 No. 3, pp. 326-348.

Perck, J., Van Hoecke, J., Westerbeek, H. and Breesch, D. (2016), Organisational change in local sport clubs: the case of Flemish gymnastics clubs, Sport, Business and Management: An International Journal, Vol. 6 No. 2, pp. 158-181.

Pfeffer, J. and Salancik, G. B. (1978), The external control of organizations, Harper and Row, New York.

Pugh, D.S., Hickson, D.J., Hinings, C.R. and Turner, C. (1968), Dimensions of organization structure, Administrative Science Quarterly, Vol. 13 No. 1, pp.65-105.

Robinson, L. (2010), The Operating Environment of Voluntary Sport Organisations. In Robinson, L., and Palmer, D. (Eds.), Managing Voluntary Sport Organizations, Routledge, New York, NY. 
Shilbury, D. and Ferkins, L. (2011), Professionalisation, sport governance and strategic capability, Managing Leisure, Vol. 16 No. 2, pp. 108-127.

Shilbury, D. and Moore, K.A. (2006), A study of organizational effectiveness for national Olympic sporting organizations, Nonprofit and Voluntary Sector Quarterly, Vol. 35 No. 1, pp. 5-38.

Slack, T. and Hinings, B. (1994), Institutional pressures and isomorphic change: An empirical test, Organization Studies, Vol. 15 No. 6, pp. 803-827.

Solntsev, I., and Osokin, N. (2018). Designing a performance measurement framework for regional networks of national sports organizations: evidence from Russian football. Managing Sport and Leisure, pp. 1-21.

Thompson, J.D. (1967). Organisations in Action. McGraw-Hill. New York.

Thibault, L., Slack, T. and Hinings, B. (1991), Professionalism, structures and systems: The impact of professional staff on voluntary sport organizations, International Review for the Sociology of Sport, Vol 26 No. 2, pp. 83-98.

Tosi, H. L. (1992). The Environment/Organisation/Person Contingency Model: A Meso Approach to the Study of Organisations. Greenwich, CT: JAI Press.

U.K. Sport., 2004. Good governance guide for national governing bodies. London: UK Sport, Vol. 11.

Vos, S., Breesch, D., Késenne, S., Van Hoecke, J., Vanreusel, B. and Scheerder, J. (2011), Governmental subsidies and coercive pressures. Evidence from sport clubs and their resource dependencies, European Journal for Sport and Society, Vol. 8 No. 4, pp. 257-280.

Wellens, L. and Jegers, M. (2014), Effective governance in nonprofit organizations: A literature based multiple stakeholder approach, European Management Journal, Vol. 32 No. 2, pp. 223-243. 
Wicker, P. and Breuer, C. (2011), Scarcity of resources in German non-profit sport clubs, Sport Management Review, Vol. 14 No. 2, pp. 188-201.

Wicker, P., Breuer, C. and Hennigs, B. (2012), Understanding the interactions among revenue categories using elasticity measures - Evidence from a longitudinal sample of non-profit sport clubs in Germany, Sport Management Review, Vol. 15 No. 3, pp. 318-329.

Winand, M., Rihoux, B., Robinson, L., and Zintz, T. (2013). Pathways to high performance: A qualitative comparative analysis of sport governing bodies. Nonprofit and Voluntary Sector Quarterly, Vol 42 No 4, pp 739-762.

Winand, M., Rihoux, B., Qualizza, D., and Zintz, T. (2011) Combinations of Key Determinants of Performance in Sport Governing Bodies, Sport, Business and Management: An International Journal. Vol 1 No 3, pp 234-251.

Winand, M., Vos, S., Claessens, M., Thibaut, E. and Scheerder, J. (2014), A unified model of non-profit sport organizations performance: perspectives from the literature, Managing Leisure, Vol. 19 No. 2, pp. 121-150.

Winand, M., Vos, S., Zintz, T., and Scheerder, J. (2013), Determinants of Service Innovation: a Typology of Sports Federations, International Journal of Sport Management and Marketing, Vol 13 No 1 - 2, pp. 55-73.

Winand, M., Zintz, T., Bayle, E. and Robinson, L. (2010), Organizational performance of Olympic sport governing bodies: dealing with measurement and priorities, Managing Leisure, Vol 15 No. 4, pp.279-307.

Zeithaml, V. A., Rajan Varadarajan, P., and Zeithaml, C. P. (1988). The contingency approach: its foundations and relevance to theory building and research in marketing. European Journal of Marketing, Vol 22 No. 7, pp.37-64. 
Table 1: Performance Management in National Sport Organisations

\begin{tabular}{|c|c|c|}
\hline $\begin{array}{l}\text { Author(s) } \\
\text { and year }\end{array}$ & Sample & Findings \\
\hline Frisby, 1986 & $\begin{array}{l}29 \text { Canadian National } \\
\text { Sport Organisations }\end{array}$ & $\begin{array}{l}\text { Characteristics of bureaucracy prevalent among NSOs increases their likelihood of } \\
\text { goal and system effectiveness. Furthermore, organisational design and structural } \\
\text { characteristics of NSOs influence their organisational performance. }\end{array}$ \\
\hline $\begin{array}{l}\text { Chelladurai } e t \\
\text { al., } 1987\end{array}$ & $\begin{array}{l}48 \text { Canadian National } \\
\text { Sport Organisations }\end{array}$ & $\begin{array}{l}\text { Organisational effectiveness is a multi-dimensional construct that includes six } \\
\text { system-based dimensions of inputs (human and monetary resources), throughputs } \\
\text { (mass and elite sport) and outputs (mass and elite sport). }\end{array}$ \\
\hline $\begin{array}{l}\text { Chelladurai } \\
\text { and Haggerty, } \\
1991\end{array}$ & $\begin{array}{l}51 \text { Canadian National } \\
\text { Sport Organisations }\end{array}$ & $\begin{array}{l}\text { Individuals within NSO can have differing perceptions regarding process } \\
\text { effectiveness as perceived by volunteers and professional staff of Canadian NSOs. }\end{array}$ \\
\hline $\begin{array}{l}\text { Papadimitriou } \\
1998\end{array}$ & $\begin{array}{l}20 \text { Greek National } \\
\text { Sport Organisations }\end{array}$ & $\begin{array}{l}\text { NSOs operate in highly institutionalized contexts because they are funded and } \\
\text { controlled by state agencies. As such NSOs perform poorly because of influences on } \\
\text { their institutional processes and internal organisational behaviour. Therefore, external } \\
\text { and internal environmental conditions influence the NSO organisational performance. }\end{array}$ \\
\hline $\begin{array}{l}\text { Papadimitriou } \\
\text { and Taylor, } \\
2000\end{array}$ & $\begin{array}{l}20 \text { Greek National } \\
\text { Sport Organisations }\end{array}$ & $\begin{array}{l}\text { Demonstrates the utility of the multiple constituency approach to measuring the } \\
\text { effectiveness of NSOs and identifies performance dimensions that include stability of } \\
\text { the board and key strategic partnerships, athlete development, internal processes, } \\
\text { strategic planning, and the use of emerging sport science. Organisational performance } \\
\text { is a multi-dimensional and multi-perceptual construct and there is need to identify } \\
\text { and reconcile the multiple demands of interest groups to facilitate an environment } \\
\text { that fosters organisational effectiveness. }\end{array}$ \\
\hline $\begin{array}{l}\text { Bayle and } \\
\text { Madella, } \\
2002\end{array}$ & $\begin{array}{l}40 \text { French National } \\
\text { Sport Organisations }\end{array}$ & $\begin{array}{l}\text { Organisational performance is a multi-dimensional construct and identifies } \\
\text { performance dimensions that include institutional, social internal, social external, } \\
\text { finance, publicity and organisational. The study further proposes a measurement } \\
\text { model based on these dimensions. }\end{array}$ \\
\hline $\begin{array}{l}\text { Madella et } \\
\text { al., } 2005\end{array}$ & $\begin{array}{l}\text { National Swimming } \\
\text { Federations in } \\
\text { Portugal, Spain, Italy } \\
\text { and Greece }\end{array}$ & $\begin{array}{l}\text { Proposes a performance measurement approach that combines input and process } \\
\text { variables and output measures. Further identifies dimensions that include human } \\
\text { resources, finance and institutional communication, partnership and inter- } \\
\text { organisational relations, volume and quality of services, athletes' international } \\
\text { performance. Furthermore, the study concludes on the multidimensionality of } \\
\text { organisational performance. }\end{array}$ \\
\hline $\begin{array}{l}\text { Shilbury and } \\
\text { Moore, } 2006\end{array}$ & $\begin{array}{l}10 \text { Australian } \\
\text { Olympic Sport } \\
\text { Organisations }\end{array}$ & $\begin{array}{l}\text { Uses competing values approach to measure organisational effectiveness of NSOs } \\
\text { and identifies determinants of effectiveness that include productivity, flexibility, } \\
\text { resources, planning, information, stability. Highlights the influence of the varying } \\
\text { needs and expectations of multiple constituents of NSOs on organisational } \\
\text { effectiveness. }\end{array}$ \\
\hline $\begin{array}{l}\text { Bayle and } \\
\text { Robinson, } \\
2007\end{array}$ & $\begin{array}{l}11 \text { French Sport } \\
\text { Organisations }\end{array}$ & $\begin{array}{l}\text { The study focussed on the performance management of NSOs and proposes a } \\
\text { framework for managing organisational performance based on the strategic } \\
\text { performance mix and operational performance mix. }\end{array}$ \\
\hline $\begin{array}{l}\text { Winand et al., } \\
2010\end{array}$ & $\begin{array}{l}27 \text { Olympic Sport } \\
\text { Organisations in } \\
\text { Belgium }\end{array}$ & $\begin{array}{l}\text { Developed a model that measures organisational performance based on strategic } \\
\text { objectives and operational goals and performance dimensions that include sport, } \\
\text { customer, communication and image, finance, organisation. }\end{array}$ \\
\hline
\end{tabular}




\begin{tabular}{|l|l|l|}
\hline $\begin{array}{l}\text { Winand } \text { et al., } \\
\text { 1811 National Sport } \\
\text { Organisations in } \\
\text { Belgium }\end{array}$ & $\begin{array}{l}\text { The study highlights possible success factors related to high performance of NSOs } \\
\text { and consider organisational performance from perspectives that include focus on elite } \\
\text { sport, developing innovative activities, the use of volunteer expertise and suggest } \\
\text { combinations of key determinants linked with high performance of NSOs. }\end{array}$ \\
\hline $\begin{array}{l}\text { Winand } \text { et al., } \\
2013\end{array}$ & $\begin{array}{l}\text { 18 National Sport } \\
\text { Organisations in } \\
\text { Belgium }\end{array}$ & $\begin{array}{l}\text { The study established that high performance could be achieved by NSOs that were } \\
\text { innovative in developing activities and delivering elite services to their members. The } \\
\text { study further highlights the importance of involving paid staff and volunteers in } \\
\text { decision making processes. }\end{array}$ \\
\hline $\begin{array}{l}\text { O'Boyle and } \\
\text { Hassan 2014 }\end{array}$ & Literature review & $\begin{array}{l}\text { The study reviewed sport management literature on organisational performance } \\
\text { among NSOs and concluded that most of the studies conducted between 1986 and } \\
\text { 2014, focussed more on performance measurement rather than performance } \\
\text { management. }\end{array}$ \\
\hline $\begin{array}{l}\text { O'Boyle and } \\
\text { Hassan, 2015 }\end{array}$ & $\begin{array}{l}\text { Case study of 3 NSOs } \\
\text { in New Zealand }\end{array}$ & $\begin{array}{l}\text { The practice of PM among NSOs in New Zealand was at evolutionary stages with } \\
\text { some NSOs implementing aspects of the practice and some NSOs not practicing } \\
\text { performance management at all. The study further highlights the importance of NSOs } \\
\text { to implement PM. }\end{array}$ \\
\hline $\begin{array}{l}\text { Solntsev and } \\
\text { Osokin, 2018 }\end{array}$ & $\begin{array}{l}\text { 10 inter-regional } \\
\text { Football Associations } \\
\text { of the Football Union } \\
\text { of Russia }\end{array}$ & $\begin{array}{l}\text { The study developed a performance measurement model that measures organisational } \\
\text { performance based on context (Russian) specific dimensions that include player } \\
\text { development, elite sport, grassroot infrastructure and development and promotion } \\
\text { activities. The measurement tool that they developed evaluates the level of football } \\
\text { development in Russia. }\end{array}$ \\
\hline
\end{tabular}


Figure 1 Holistic theoretical model of PM for NSO

Figure 1: Holistic Theoretical Model of Performance Management for National Sport Organisations

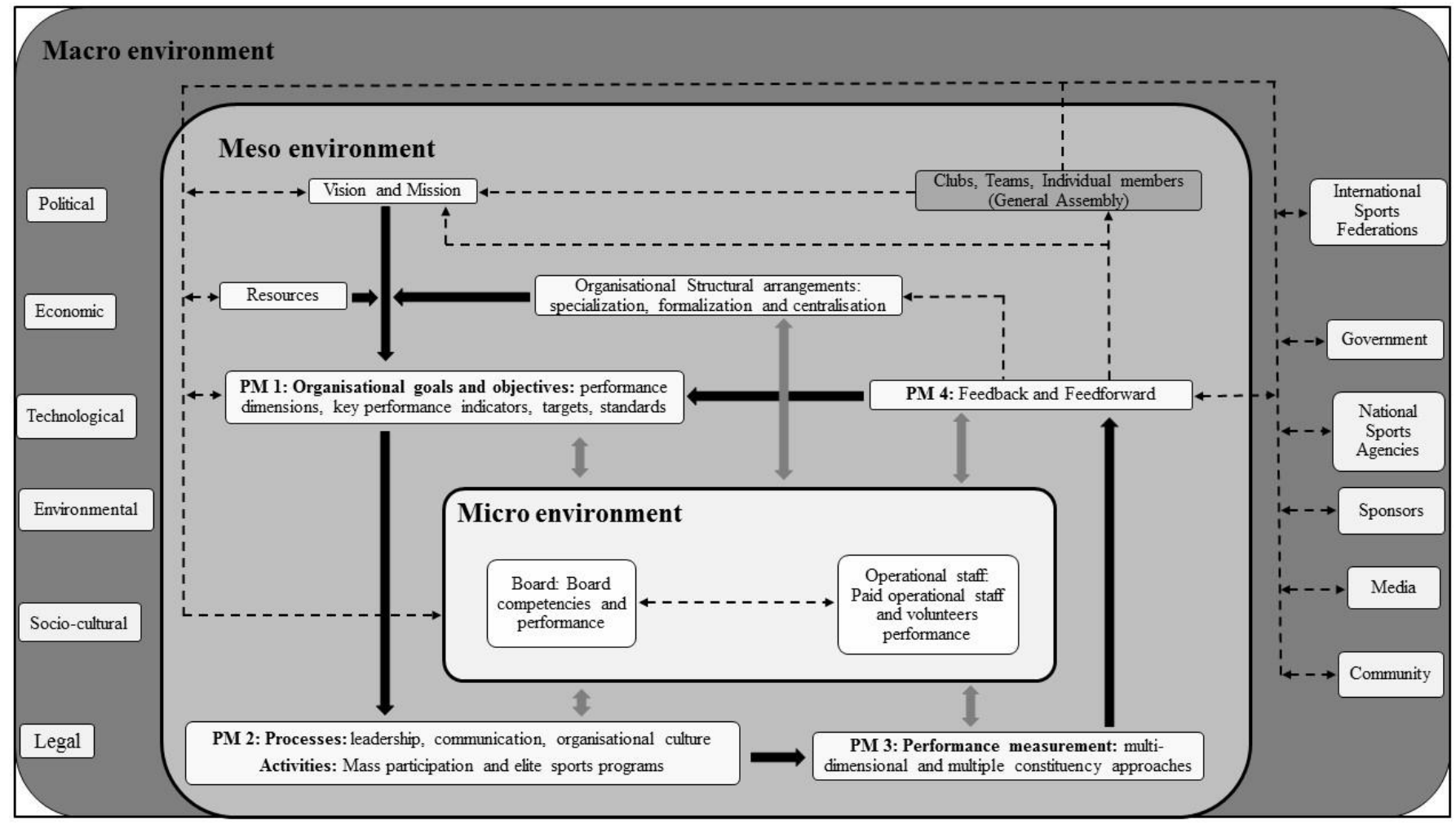

\section{Legend}

Performance management process

Interaction between the people within the NSO and the stages of the performance management process

$---\rightarrow$ Flow of information 
Table 2: Components of a PM model

\begin{tabular}{|c|c|c|}
\hline Otley (1999) and Ferreira and Otley (2009) & Kaplan and Norton, (1992) & Bayle and Robinson (2007) \\
\hline $\begin{array}{ll}\text { 1. } & \text { Organisational vision and mission } \\
\text { 2. } & \text { Organisational structure } \\
\text { 3. } & \text { Strategies and plans } \\
\text { 4. } & \text { Key performance measures } \\
\text { 5. } & \text { Targets } \\
\text { 6. } & \text { Evaluation processes } \\
\text { 7. } & \text { Rewards } \\
\text { 8. } & \text { Feedback and Feedforward } \\
\text { 9. } & \text { Learning curve } \\
\text { 10. } & \text { Influence of external environment } \\
\text { 11. } & \text { Interdependence of operating system }\end{array}$ & $\begin{array}{l}\text { 1. Customer perspective: General mission } \\
\text { 2. Internal business perspective: Organisational } \\
\text { processes and competencies. } \\
\text { 3. Innovation and learning: ability to improve } \\
\text { 4. Finance: Profits growth and shareholder value. } \\
\begin{array}{|ll|}\text { Neely, Adams and Crowe, (2001) } \\
\text { 1. } & \text { Stakeholder satisfaction } \\
\text { 2. } & \text { Stakeholder contribution } \\
\text { 3. } & \text { Strategies } \\
\text { 4. } & \text { Processes } \\
\text { 5. } & \text { Capabilities }\end{array}\end{array}$ & $\begin{array}{l}\text { 1. Strategic performance } \\
\text { a. The system of governance } \\
\text { b. Quality of the operating framework } \\
\text { c. Position of the NSO system. } \\
\text { 2. Operational performance mix } \\
\text { b. } \\
\text { i. Facilitators } \\
\text { ii. } \\
\text { Forms of level of professionalisation. } \\
\text { Participatory organisational culture. } \\
\text { a. Inhibitors } \\
\text { i. } \\
\text { ii. } \\
\text { iii. } \\
\text { iv. }\end{array}$ \\
\hline
\end{tabular}

